\title{
Terminologia dels exercicis de força amb sobrecàrregues (III)
}

\section{Terminology of Overload Strength Training Exercises (III)}

\section{FRANCESC COS MORERA}

Institut Nacional d'Educació Física de Catalunya - Centre de Barcelona

Preparador físic del FC Barcelona

\section{MICHEL MARINA EVRARD}

Institut Nacional d'Educació Física de Catalunya - Centre de Barcelona

JORDI PORTA MANCEÑIDO

Institut Nacional d'Educació Física de Catalunya - Centre de Barcelona

Autor per a la correspondència

Francesc Cos Morera

fcos@gencat.cat

\section{Resum}

Les ciències aplicades a l'activitat física i a l'esport són relativament recents i han d'estandarditzar encara el seu vocabulari en algunes àrees de coneixement. Establir una terminologia de consens $i$ unívoca en relació amb els exercicis de força amb sobrecàrregues és fonamental per les persones professionals que treballen en les ciències de l'exercici físic i el cos humà. Es imprescindible articular una terminologia vehicular en aquest sector d'intervenció social de gran repercussió. El dret a la lliure circulació de persones pels països de la Unió Europea i, en general, la globalització, fan necessari també el coneixement de la terminologia de la musculació en altres llengües vehiculars. El següent article es el tercer d'una sèrie de quatre i presenta els exercicis més representatius d'esquena, abdominals $i$ estabilitzadors en versió catalana, castellana i anglesa, amb l'objectiu que conformin una base de gran abast que permeti definir altres exercicis.

Paraules clau: terminologia exercici, força, musculació, terminologia unívoca

\begin{abstract}
Terminology of Overload Strength Training Exercises (III)

Science applied to physical activity and sport is relatively recent and has yet to standardize its vocabulary in some areas of knowledge. Establishing an agreed and unambiguous terminology in relation to strength training is essential for professionals working in exercise and human body science. It is crucial to draw up unambiguous terminology in this area of high-impact social action. The right to free movement of people across European Union member states and globalization in general also calls for knowledge of bodybuilding terminology in other languages. The following paper is the third in a series of four and presents the most common back, abdominals and satbilisers exercises in Spanish, Catalan and English. It is designed to be a wide-ranging basis for definitions for other exercises.
\end{abstract}

Keywords: exercise terminology, strength, bodybuilding, unambiguous terminology

\section{Introducció}

Una de les característiques de les diferents ciències i tecnologies aplicades és la capacitat de crear un vocabulari específic, que té com a objectiu facilitar l'entesa entre els professionals d'àrees de coneixement afins. Les ciències aplicades a l'activitat física i a l'esport són relativament joves i han d'estandarditzar encara el seu vocabulari en algunes àrees.

En el moment de conceptualitzar cadascun dels exercicis fonamentals de força, ens adonem que tradicionalment s'han seguit criteris molt diversos; així, per exemple: s'utilitza indistintament el nom del múscul que hi participa; es parla de l'acció que fa l'articulació; es defineix l'acció que s'està produint o bé s'anomena a partir del nom del material que s'utilitza. Exemples:
- nom del múscul que hi participa: puntada de tríceps

- nom segons l'acció que fa l'articulació: extensions de genoll a la màquina

- nom de l'acció que s'està produint: elevacions frontals

- nom del material que s'utilitza: rull Scott

Aquesta diversitat a l'hora de definir els exercicis fa molt difícil establir una terminologia tenint en compte un criteri únic. Així, doncs, ens trobem davant un vocabulari específic que s'ha creat amb una manca de justificació tècnica, sobretot pel que fa a les versions castellana i catalana, que han seguit amb gran freqüència la versió anglesa com a única font d'inspiració. 


\begin{tabular}{cc} 
Criteris & \multicolumn{1}{c}{ Descripció } \\
Primer & $\begin{array}{l}\text { - Quan la terminologia que defineix l'exercici és àmpliament reconeguda, es manté sempre que no re- } \\
\text { presenti una incorrecció. }\end{array}$ \\
Segon & - Pel que fa als exercicis monoarticulars és adequat definir-los d'acord amb la posició anatòmica fona- \\
& mental; aquesta definició pot coexistir amb la tradicional. \\
Tercer & - Pel que fa als exercicis poliarticulars, la definició segons la posició anatòmica fonamental sol ser mas- \\
& sa llarga. Paraules que descriuen l'acció i el moviment faciliten la descripció (rem, tisores, carregada, \\
Quart & projecció, etc.). \\
& La definició d'acord amb la musculatura que hi participa no sol ésser recomanable, ja que molt sovint \\
& és inexacta o incompleta. Si no és imprescindible, definirem l'exercici tenint en compte l'acció que es \\
produeix a l'articulació.
\end{tabular}

L'objectiu fonamental d'aquest article és establir una terminologia de consens en relació amb els exercicis de força amb sobrecàrregues que permeti a les persones professionals que treballen en les ciències de l'exercici físic disposar d'una nomenclatura i llenguatge propis.

D'altra banda, l'Estat espanyol és membre de ple dret de la Unió Europea des de l'any 1986. La Unió monetària i econòmica i el dret a la lliure circulació de persones són mesures que afavoriran l'intercanvi de professionals entre diferents estats membres. Un altre fet que afavorirà aquests possibles canvis de residència és la declaració de Bolonya de l'any 1999 , que té com a objectiu la unificació de les titulacions acadèmiques en l'àmbit europeu. Així mateix, la inclusió en aquest treball de les versions en castellà i anglès facilitarà l'entesa entre un major nombre de professionals.

\section{Metodologia}

\section{Criteris per a la descripció dels exercicis}

En l'article publicat en el número 103 (1r trimestre de 2011) de la revista Apunts. Educació Física i Esports, s'han editat de forma completa els criteris que s'han seguit per a la descripció dels exercicis. En aquesta tercera edició es presenten els criteris de forma resumida (taula 1).

\section{Interpretació de la definició dels exercicis}

S'ha escrit amb negreta el nom genèric de l'exercici, mentre que la part que explica les característiques específiques de l'exercici es fa en lletra rodona normal. Les formes sinònimes estan separades pel símbol /. Entre parèntesis es descriuen variants d'execució per a un mateix exercici.

\section{Símbols utilitzats}

La rodona negreta $(\bullet)$ per a la versió catalana, la rodona blanca (O) per a la versió castellana i el quadratí blanc ( $\square)$ per a la versió anglesa.

- català, $\bigcirc$ castellà, $\square$ anglès

\section{Procediment}

S'han distribuit els exercicis per regions corporals. L'elecció dels exercicis no obeeix a criteris de salut o rendiment, sinó que s'han proposat els més representatius en l'elaboració de les rutines de musculació, així com en la bibliografia de referència: en l'àmbit de la cinesiologia (per exemple, Aeberg, 1998; Enoka, 1994; Floyd \& Thompson, 2004), en el de la musculació per a la salut (Beachle \& Groves, 1998; Darden, 1990; Kinakin, 2004; Salter, 1999; entre d'altres), en el de la musculació estètica (Llucià, 2001; Schwarzenegger, 1985) o en diccionaris de l'esport (Bañeres, De Seabra, \& Bonet, 1989), amb l'objectiu que conformin una base suficientment àmplia que permeti definir-ne d'altres amb facilitat. Una vegada elaborat el document, s'ha lliurat a les persones professionals que treballen en diferents àmbits del món de l'activitat física i de l'entrenament per tal que en donin l'opinió en relació amb la nomenclatura.

Així mateix, també s'ha disposat del Centre de Terminologia TERMCAT per garantir l'adequació de la terminologia utilitzada en català.

\section{Agraïments}

- Al col-lega i amic Dr. Jordi Porta per haver-me descobert el món de la cinesiologia, el condicionament físic i la sistemàtica de l'exercici. 
- Al professor Dr. Juan José González Badillo per ajudar-me a mantenir-me ferm en els criteris inicials i per ser detallista en les seves correccions, com sempre.

- Als amics Joaquim Llucià i Jaume Mirallas, Juan Carlos Morante i Jorge García, per totes les argumentacions donades en cadascuna de les correccions. Opinar amb criteri és la base de la professionalitat.

- A la Sra. Glòria Fontova pels seus generosos informes, pel seu inestimable ajut.

- A tots els professors dels INEFC de Barcelona i de Lleida, i al Centre d'Alt Rendiment de Sant Cugat del Vallès.

- A tots els especialistes que han fet aportacions: Toni Alomar, Aureli Altimira, David Álvarez, Rosa Angulo, Ramón Arús, Xavier Balius, Pau Barbat, Carlos Bernardos, Alfonso Blanco, Anthony Boddy, Enrique Bonilla, Francesc Borrell, Lorenzo Buenaventura, Albert Busquets, Martí Cabré, David Caparrós, Albert Capellas, Rocío Cárceles, David Carreras, Miquel Àngel Cos, Gabriel Daza, Glòria Fontova, Juan García, Gonzalo Gil, Carles González, Juan José González Badillo, Adrián Gutiérrez, José Vicente Ibañez, Xavi
Iglesias, Alfredo Irurtia, Mikel Izquierdo, Ramón Lacaba, Carlos Lalín, Albert Llorenç, Joaquim Llucià, Albert Marco, Jordi Mateo, Michel Marina, Marcel-lí Massafret, Alice McDowald, Jaume Mirallas, Manolo Montoya, Juan Morales, Patricia Morales, Juan Carlos Morante, Gerard Moras, Jaume Munill, Javier Olivera, Josep M. Padullés, Francisco Pascual, José Luis Pascual, Xavier Peirau, David Pérez, Jordi Porta, Joan Antoni Prat, Emili Ricart, Albert Roca, Andreu Roig, Toni Rubiella, Domingo Sánchez, Iolanda Sánchez, Francisco Seirul·lo, Isidre Sistaré, Jordi Solà, Joan Solé, Barbara Steer, Joan Ramón Tarragó, Julio Tous, Manel Vela, Carles Ventura.

- Als alumnes que han participat en el reportatge fotogràfic: Damià Abella, Gisela Álvarez, Tània González, Victor López, Alicia Montoro, Juan Morales, Patricia Morales, Jordi Palomero, Carlos Sánchez, Aurora Valls, David Villalonga.

- Al Centre de Terminologia TERMCAT, que ha col-laborat en la revisió terminològica del text de la versió en català.

Fotografia: Francesc Cos Morera 


\section{- ESQUENA}

O espalda $\square$ back
- dominació frontal amb presa ampla (mitjana, estreta)

O dominada frontal con agarre ancho (medio, estrecho)

$\square$ wide-grip (medium, close) chins-ups to the front
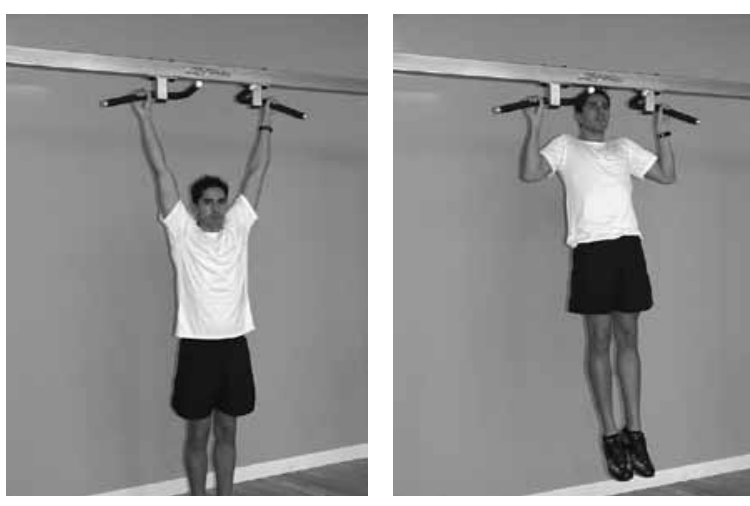

- dominació a la màquina amb presa ampla (mitjana)

O dominada en máquina con agarre ancho (medio)

$\square$ wide-grip (medium) chin-ups on machine

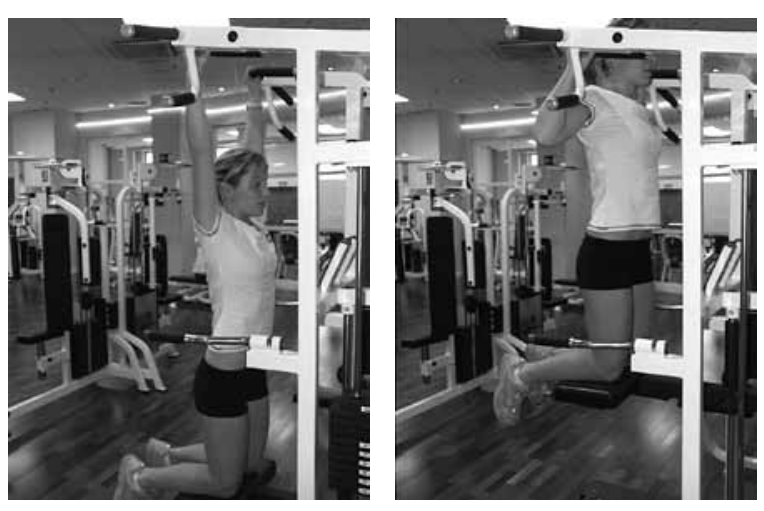

- tracció a la politja alta frontal amb presa ampla (mitjana, estreta)

$\bigcirc$ jalón / tracción en polea alta frontal con agarre ancho (medio, estrecho)

$\square$ wide-grip (medium, close) cable lat pull-down to the front
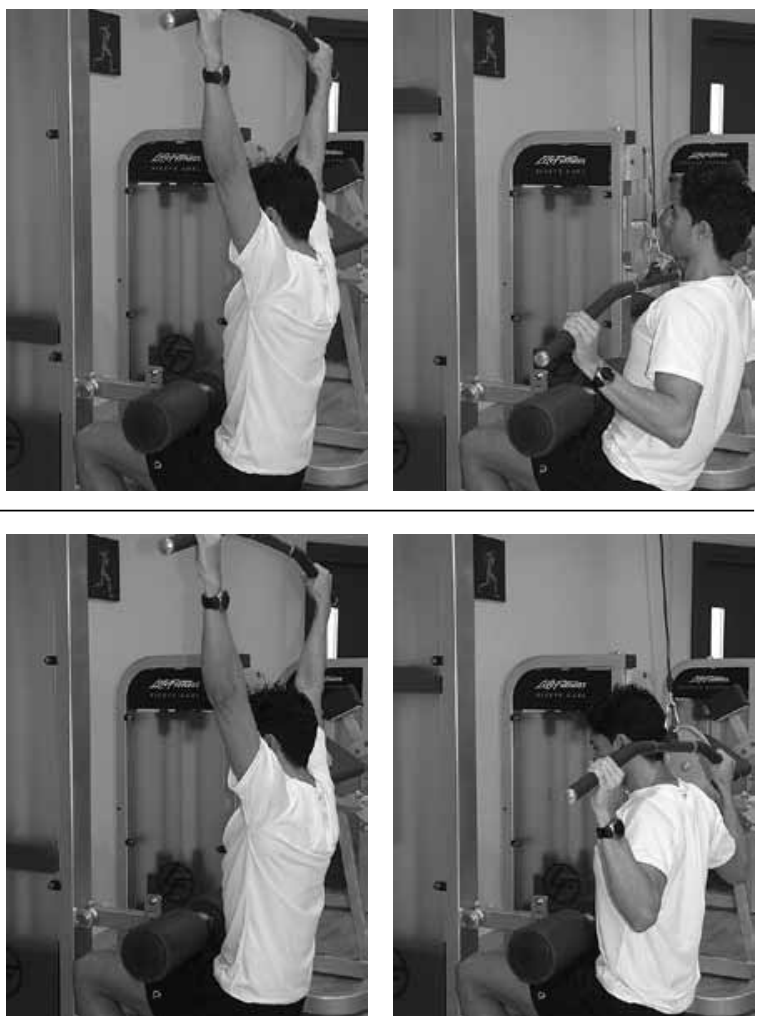

- tracció a la politja alta rere clatell amb presa ampla (mitjana)

○ jalón / tracción en polea alta tras nuca con agarre ancho (medio)

$\square$ wide-grip (medium) cable lat pull-down behind the neck / back lat pull-down 

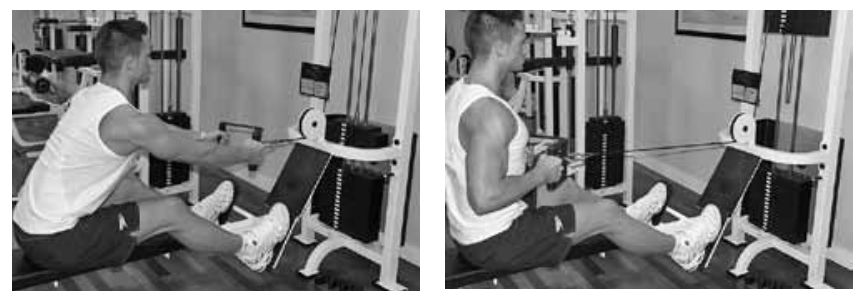

- rem a la cintura / rem Gironda a la politja baixa (amb
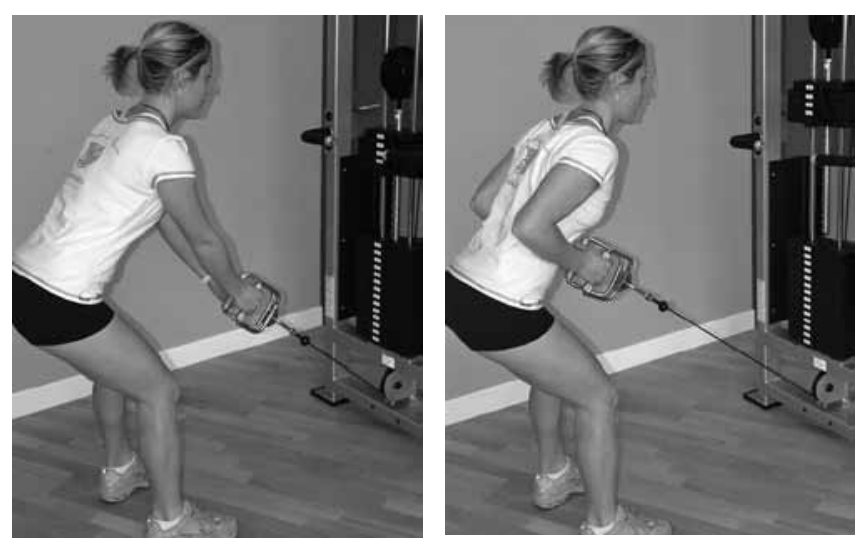
goma elàstica) assegut

O remo a la cintura / remo Gironda en polea baja (con goma elástica) sentado

$\square$ seated cable (elastic band) lat row

- rem a la cintura a la politja baixa (amb goma elàstica) dempeus

O remo a la cintura en polea baja (con goma elástica) de pie

$\square$ standing cable (elastic band) lat row
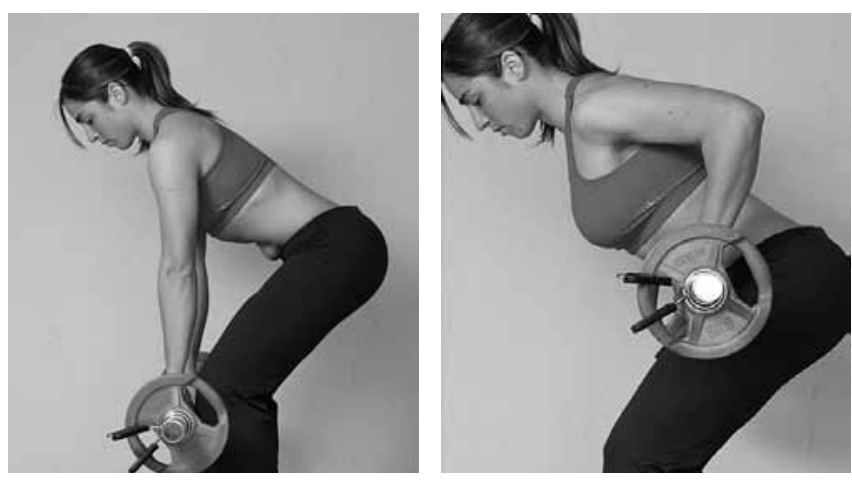

- rem a la cintura amb barra dempeus

O remo a la cintura con barra de pie

$\square$ standing bent-over barbell lat row
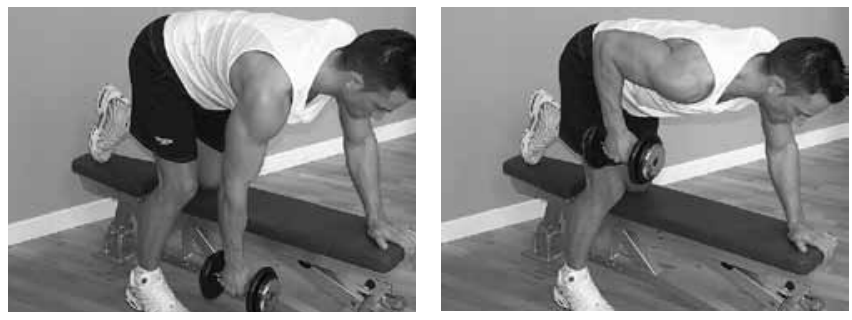

- rem a la cintura amb manuella amb una mà

O remo a la cintura con mancuerna a una mano

$\square$ one-arm dumbbell lat row
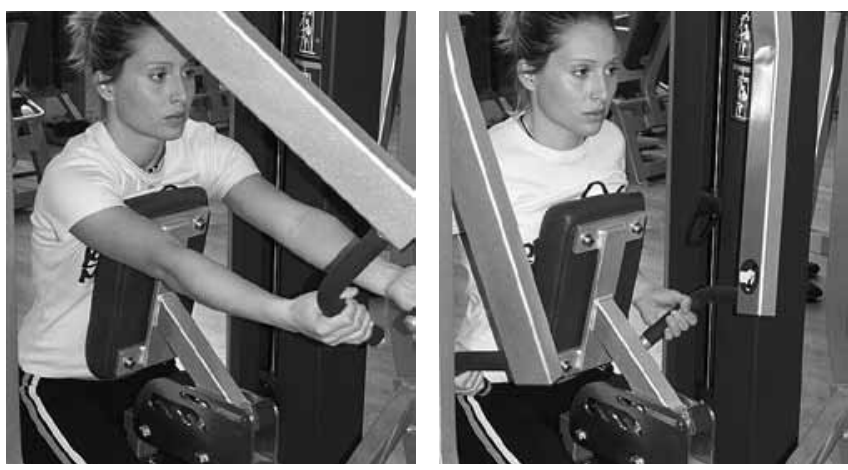

- rem a la cintura a la màquina

O remo a la cintura en máquina

$\square$ seated lat row on machine 
- rem al pit a la politja baixa (a la politja alta, amb goma elàstica) assegut (dempeus)

○ remo al pecho en polea baja (en polea alta, con goma elástica) sentado (de pie)

$\square$ seated (standing) cable (elastic band) chest row

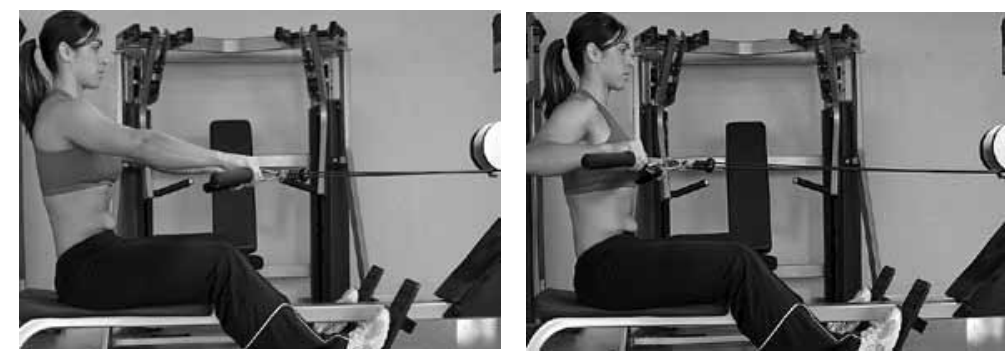

- rem al pit a la politja baixa (amb goma elàstica) dempeus (assegut)

remo al pecho en polea baja (con goma elástica) de pie (sentado)

$\square$ standing (seated) cable (elastic band) chest row
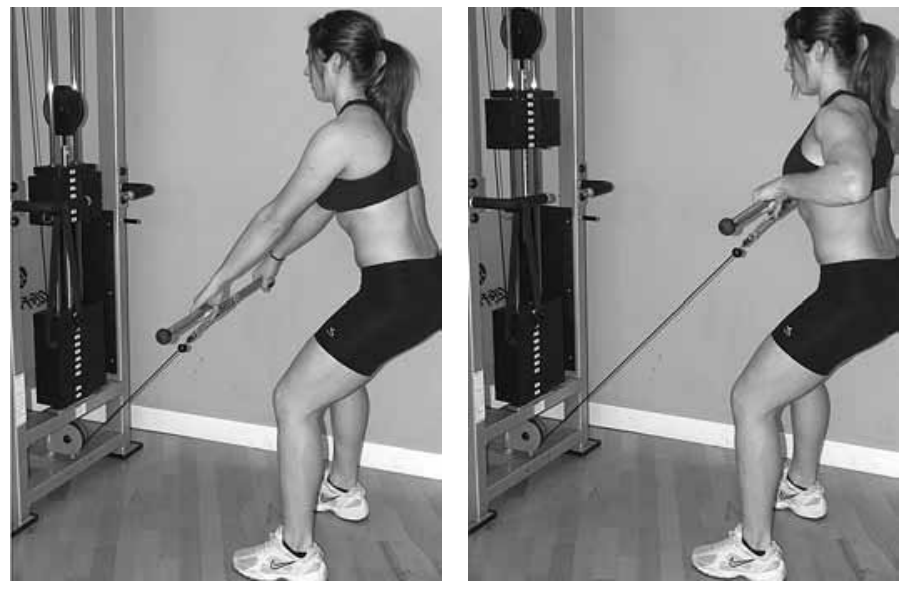

- rem al pit a la politja alta (amb goma elàstica) dempeus (assegut)

remo al pecho en polea alta (con goma elástica) de pie (sentado)

$\square$ standing (seated) cable (elastic band) chest row
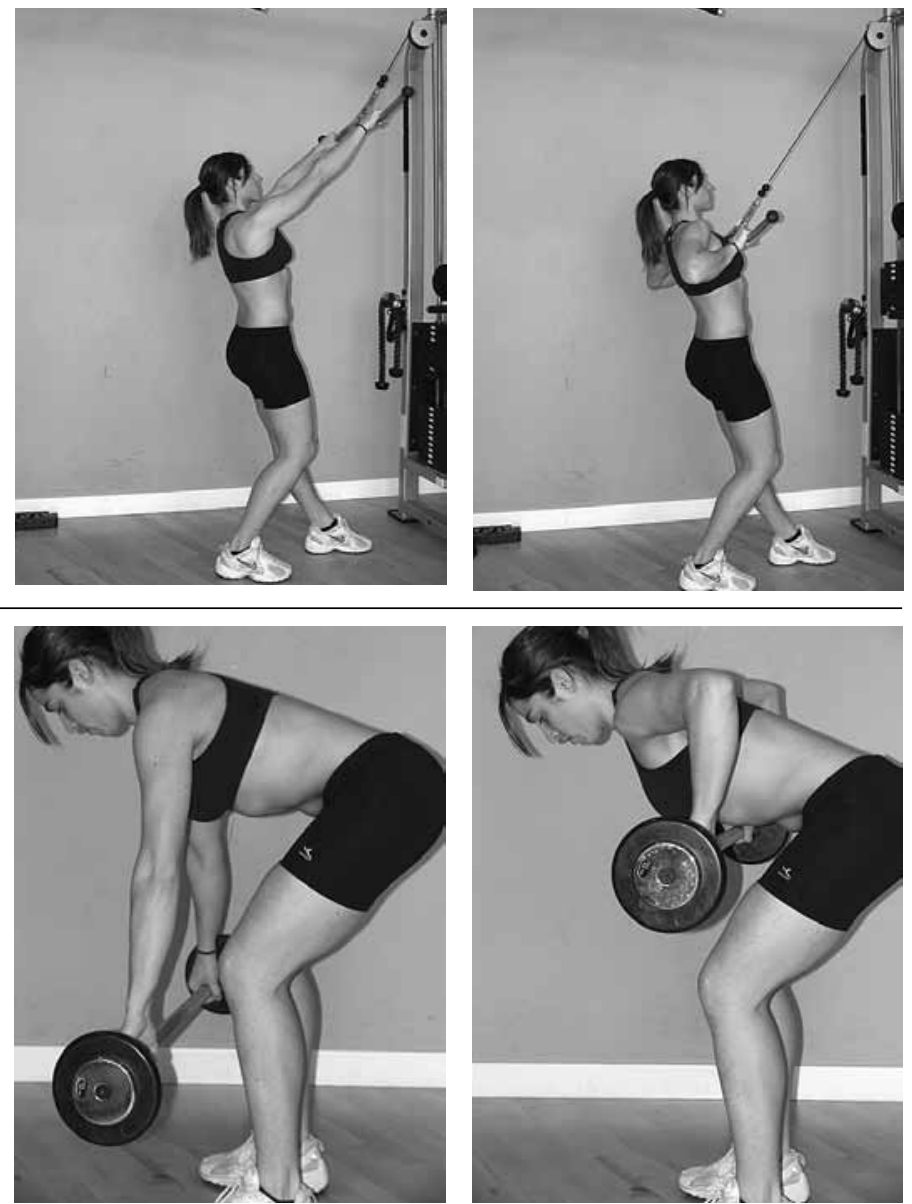

- rem al pit amb barra dempeus

O remo al pecho con barra de pie

$\square$ standing bent-over barbell chest row 

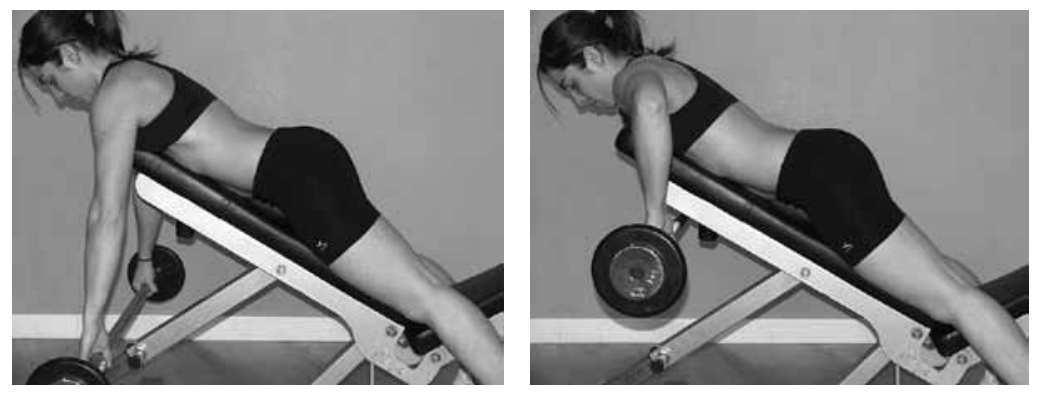

- rem al pit amb barra sobre banc inclinat (horitzontal)

remo al pecho con barra en banco inclinado (horizontal)

$\square$ bent-over barbell chest row on inclined (flat) bench
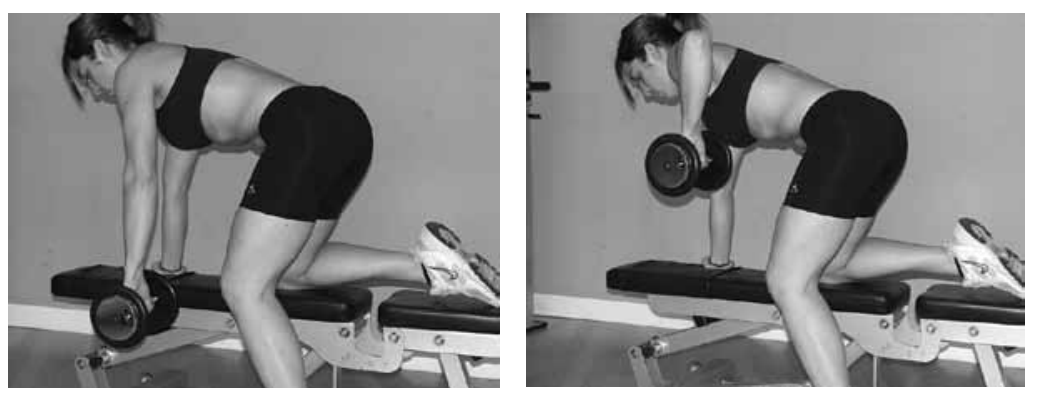

- rem al pit amb manuelles amb una mà

○ remo al pecho con mancuernas con una mano

$\square$ one-arm dumbbell chest row
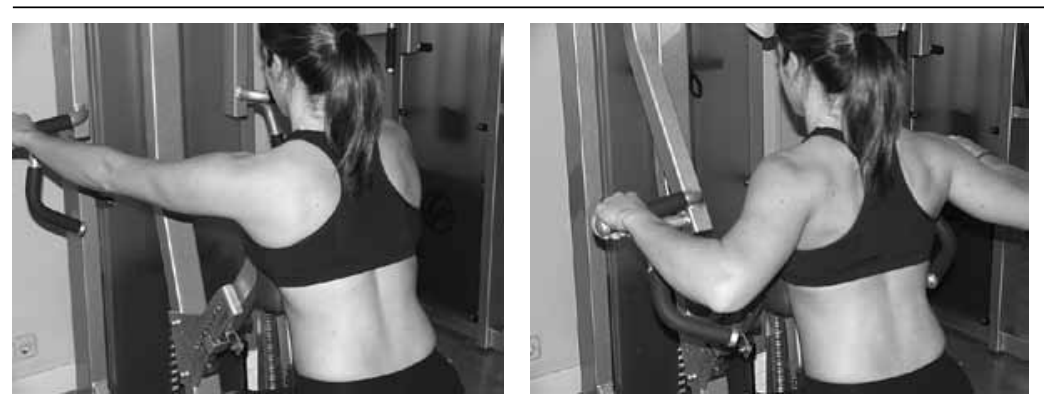

- rem al pit a la màquina

O remo al pecho en máquina

$\square$ seated chest row on machine
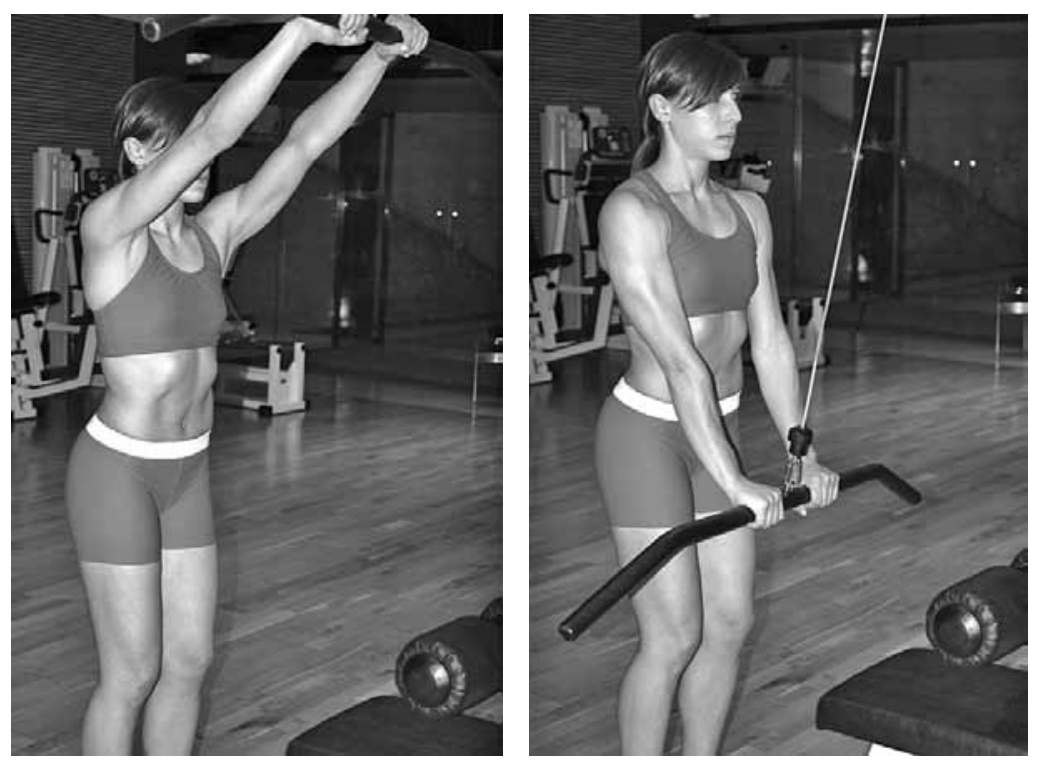

- extensió d'espatlles a la politja alta (amb goma elàstica) dempeus

O extensión de hombros en polea alta (con goma elástica) de pie

$\square$ standing straight-arm cable (elastic band) lat extension / shoulder extension / lat sweeps 
- pul·lòver / extensió d'espatlles amb barra (amb manuelles) sobre banc

o pullover / extensión de hombros con barra (con mancuernas) en banco

$\square$ barbell (dumbbells) bend-arm pullovers / shoulder extension on the bench

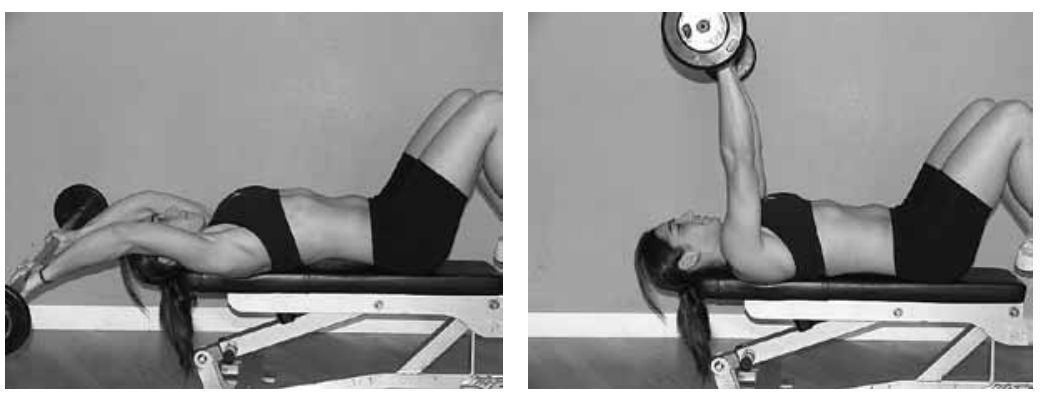

- pul·lòver / extensió d'espatlles a la màquina

○ pullover / extensión de hombros en máquina

$\square$ pullovers / shoulder extension on machine

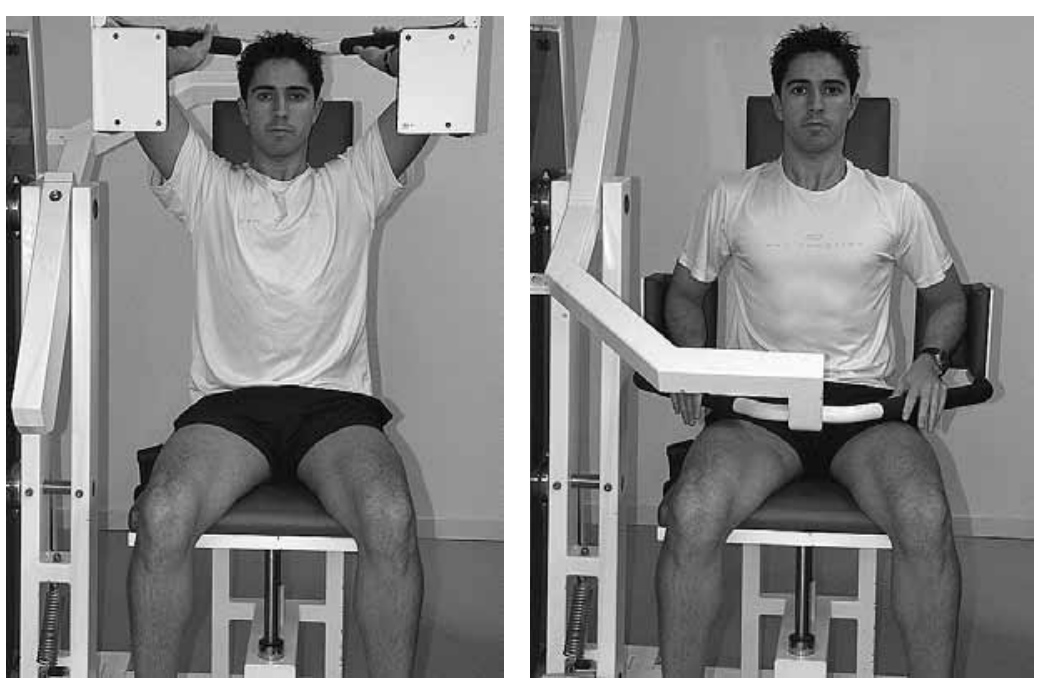

- extensió de tronc sobre banc (sobre pilota gegant)

O extensión del tronco en banco (en pelota gigante)

$\square$ inclined bench (on the fit-ball) low back lift / trunk extension
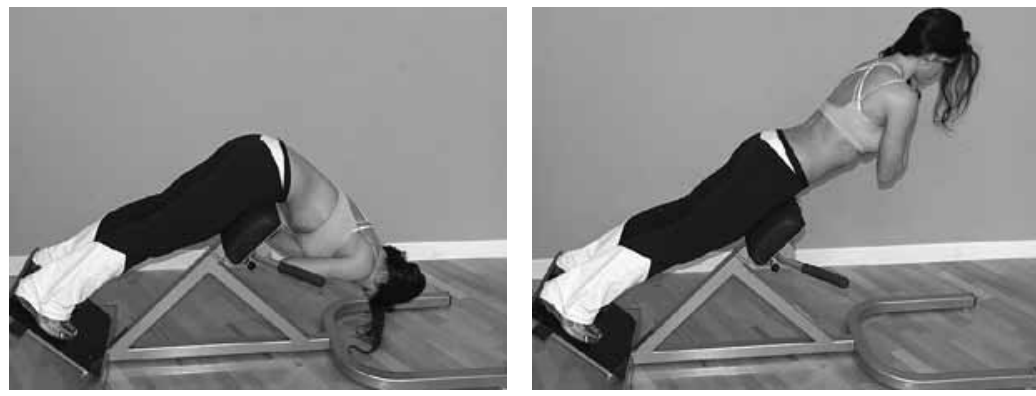

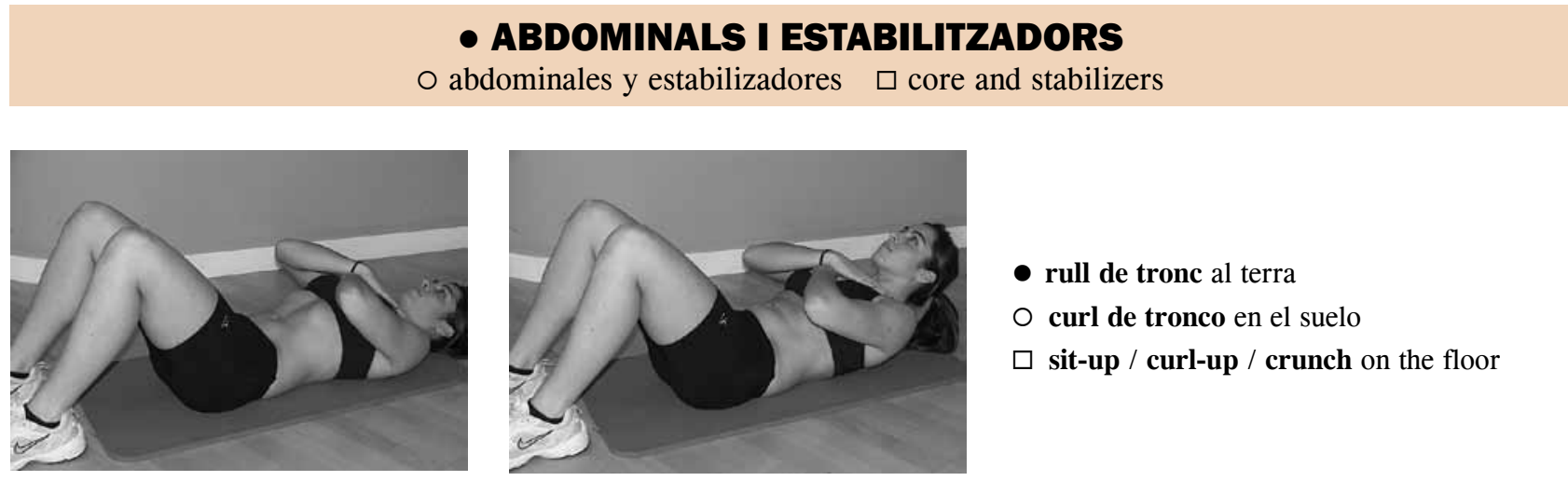

- rull de tronc al terra

o curl de tronco en el suelo

$\square$ sit-up / curl-up / crunch on the floor

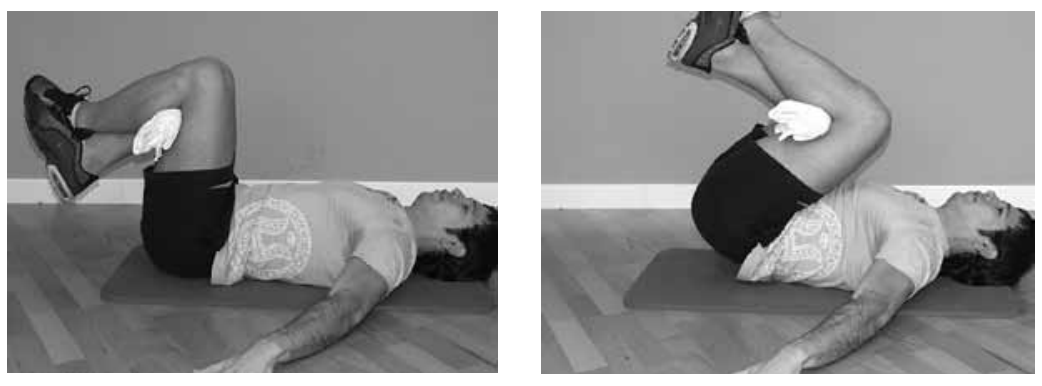

- rull de malucs al terra

O curl de caderas en el suelo

$\square$ reverse crunch / reverse sit-up / pelvic tilt on the floor
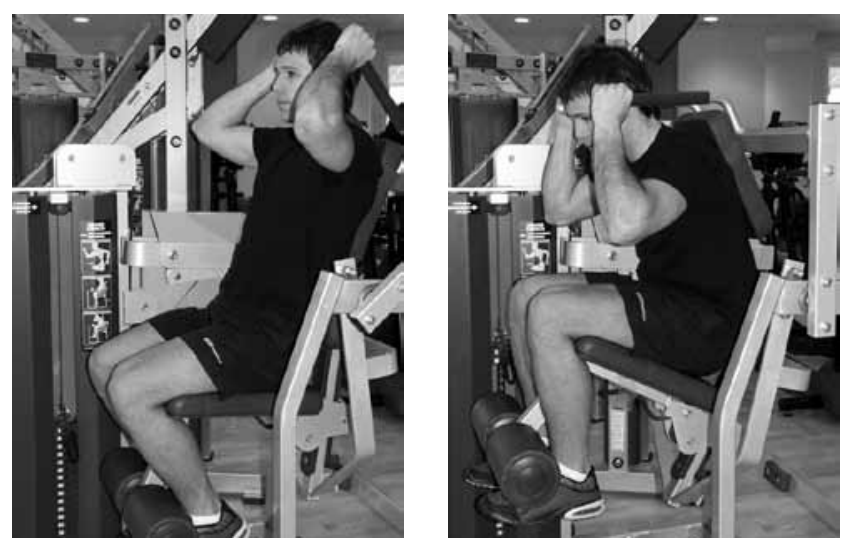

- rull de tronc a la màquina

O curl de tronco en máquina

$\square$ crunch on machine
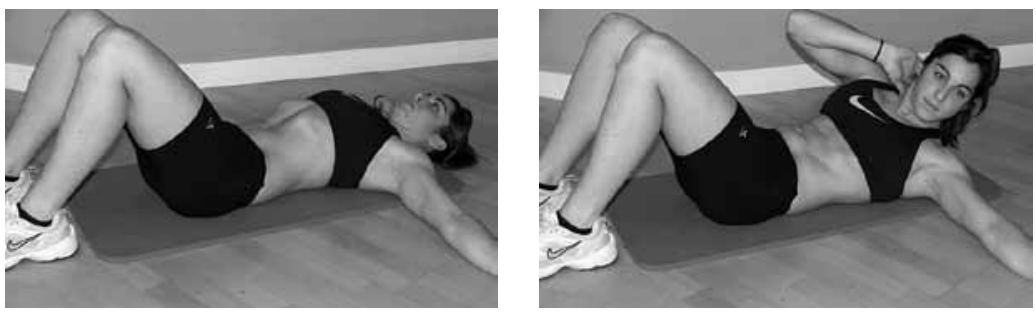

- rull de tronc amb rotació al terra

O curl de tronco con rotación en el suelo

$\square$ curl-up / sit-up / crunch with rotation on the floor
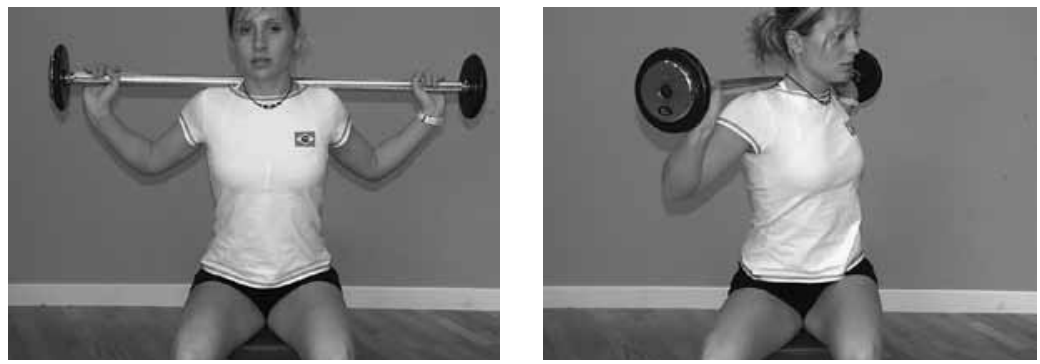

- rotació de tronc assegut (dempeus) amb barra

rotación de tronco sentado (de pie) con barra

$\square$ seated (standing) torso twist / rotary torso 
- rotació de tronc a la màquina

○ rotación de tronco en máquina

$\square$ rotary torso on machine
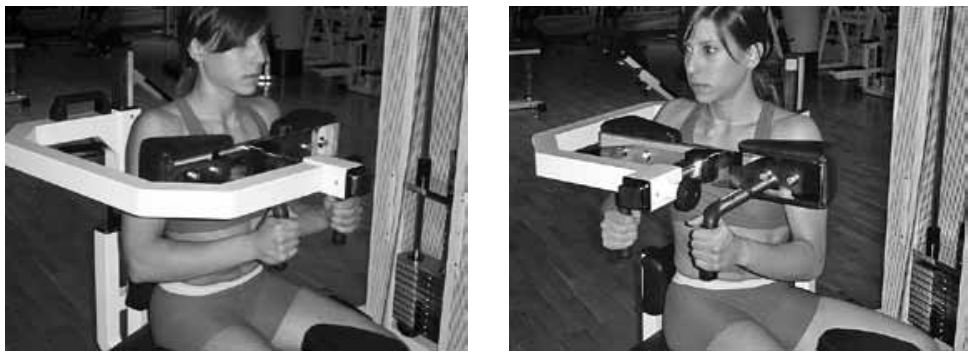

- rull de malucs sobre banc vertical

O curl de caderas en banco vertical

$\square$ reverse crunch / hips raise on vertical bench

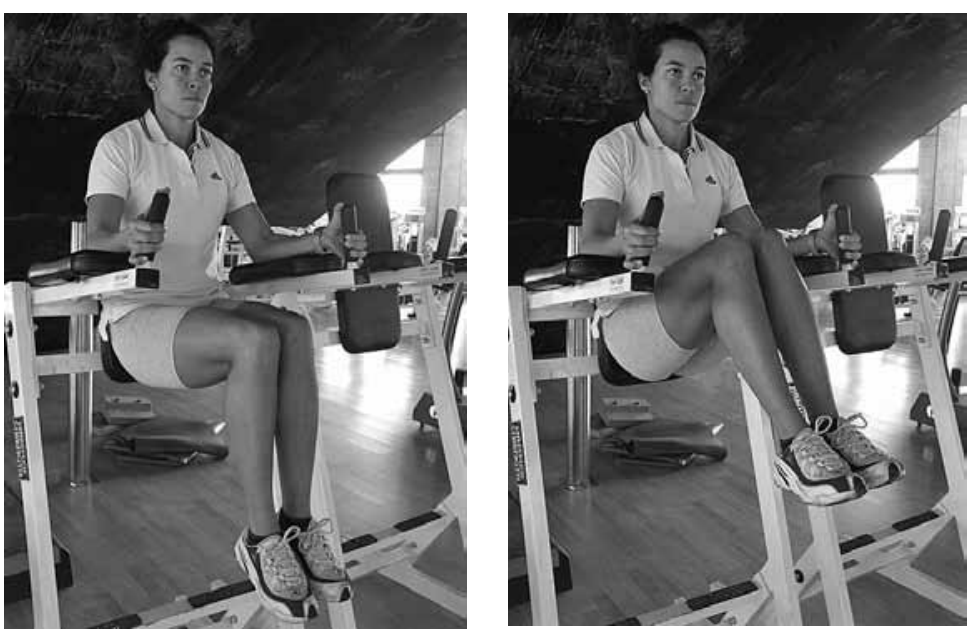

- inclinació lateral de tronc sobre banc inclinat

$O$ inclinación lateral de tronco en banco inclinado

$\square$ trunk lateral bend on inclined bench

- inclinació lateral de tronc dempeus amb manuelles

$\bigcirc$ inclinación lateral de tronco de pie con mancuernas

$\square$ standing dumbbell trunk lateral bend
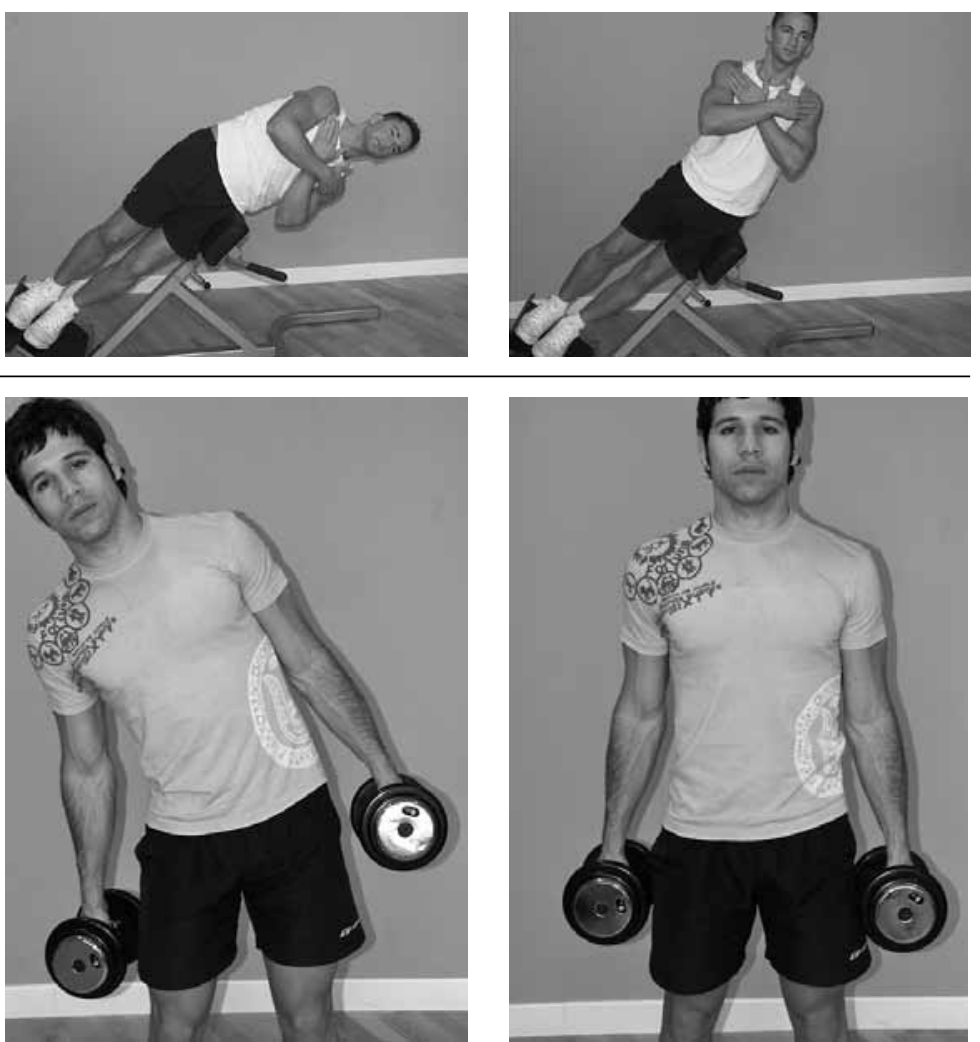

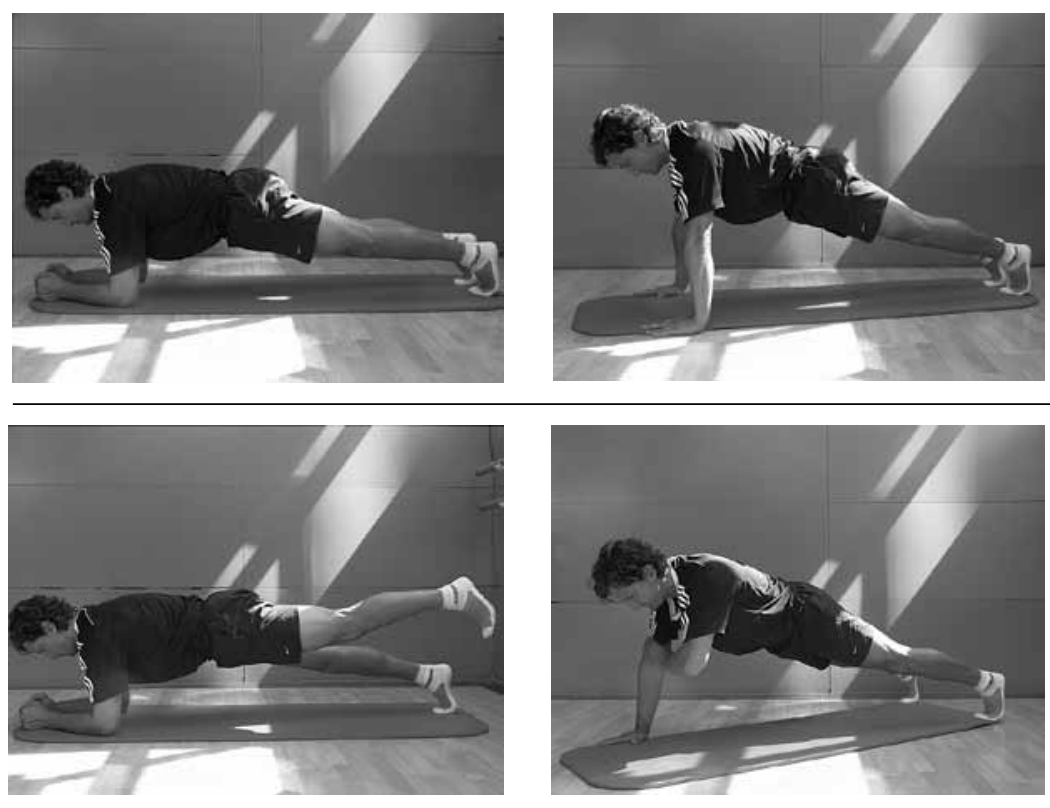

- planxa amb quatre recolzaments

plancha con cuatro apoyos

$\square$ four-point core plank
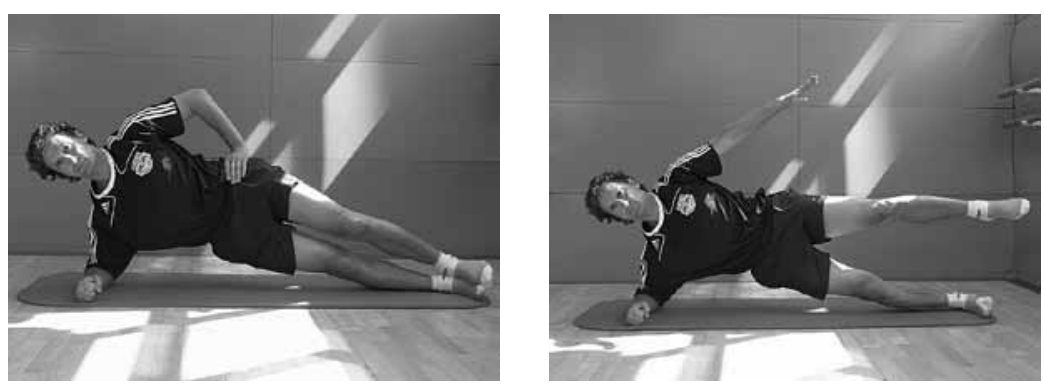

- planxa amb tres recolzaments

plancha con tres apoyos

$\square$ three-point core plank

- pont lateral (amb elevació de braç i cama)

o puente lateral (con elevación de brazo y pierna)

$\square$ (lift up arm and leg) core side bridge 


\section{Referències}

Aaberg, E. (1998). Muscle Mechanics. United Kingdom: Human Kinetics.

Baechle, T. \& Groves, B. (1998). Weight Training (2a ed.). United Kingdom: Human Kinetics.

Bañeres, E., De Seabra, M., \& Bonet, E. (1989). Diccionari de l'esport: català-castellà castellà-català. Barcelona: Enciclopèdia Catalana (Diccionaris Enciclopèdia Catalana).

Darden, E. (1990). The Nautilus Book (5a ed.). Chicago: Contemporary Books.

Enoka, R. (1994). Neuromechanical Basis of Kinesiology (2a ed.). United States: Human Kinetics.
Floyd, R. T. \& Thompson, C. W. (2004). Manual of Structural Kinesiology (15a ed.). New York: Mc Graw Hill.

Kinakin, K. (2004). Optimal Muscle Training. Champaign, IL: Human Kinetics.

Llucià, J. (2001). Musculación. Barcelona: Martínez Roca.

Salter. (ca. 1999). Pósters de musculación [Pòster]. Madrid: Instituto Municipal de Deportes.

Schwarzenegger, A. (1985). The New Encyclopedia of Modern Bodybuilding (2a ed.). New York: Simon \& Shuster.

Termcat, Centre de Terminologia. (1992). Diccionari d'halterofilia. Diccionaris dels esports olímpics (22). Barcelona: Enciclopèdia Catalana. 